\title{
Style Repertoire and Social Change in British Asian English
}

\author{
Devyani Sharma \\ Queen Mary, University of London
}

\begin{abstract}
This study has two goals: Empirically, it accounts for variation found in the use of ethnically-marked variants among British-born Asians; methodologically, it assesses the variationist approach against a repertoire approach. In Part I, one Punjabi-derived phonetic trait, examined in interview data only, suggests that younger women shift to exclusive use of the British prestige variant. Part II expands the analysis to four variables and to broader speech repertoires for four individuals. The repertoire analysis shows the conclusions in Part I to be inaccurate, and instead reveals: (i) retention of Punjabi traits by young women in the home domain, (ii) two types of repertoire-flexible and fused, (iii) a gendered reversal in repertoire type over time, and (iv) a network diversity basis for these differences. Unlike the initial variationist analysis, the use of repertoire analysis and a new network diversity index leads to the discovery of a shift among lower middle class British Asians from traditional Punjabi to urban British social structures.
\end{abstract}




\title{
Style Repertoire and Social Change in British Asian English
}

\author{
Devyani Sharma \\ Queen Mary, University of London
}

\section{INTRODUCTION}

Recent third wave approaches to sociolinguistic variation (Eckert 2005, 2008a; Agha 2007; Coupland 2007; Podesva 2007) have expanded the set of analytic lenses sociolinguists can employ in the analysis of language variation and change. As a consequence, sociolinguists working in the quantitative paradigm face renewed challenges in choosing appropriate tools for modeling and explaining sociolinguistic variation. Focusing on the use of British and Indian accent features by second generation British Asians, the present study addresses this challenge, starting with a traditional variationist approach and shifting to a repertoire approach, showing that a dramatically different picture of social change in the community emerges from each technique.

The variationist approach of examining isolated variants drawn from sociolinguistic interview data relies on a number of underlying constructs: interview speech as a reliable indicator of style range, interview style range as comparable across individuals, and social explanation as inductively observable in the interactions of a single variable with macrosocial factors. The present study shows that none of these analytic assumptions can be reliably made for individuals at the interface between communities. Although the focus here is on an ethnic minority group, this methodological claim potentially applies to any individuals with complex and intersective networks.

The initial quantitative analysis (single variable; interview data) first offers a familiar picture of female orientation to overt prestige and male orientation to the local vernacular. However, the repertoire analysis (multiple variables; multi-context data) combined with a new network diversity index reveals no such universalist male-female distinction. Instead, a reversal of gender roles appears to have taken place. I propose that this reversal relates to a transformation in the community from a more Asian, lower middle class (LMC) arrangement of gender roles to a typically British LMC and working class arrangement (Milroy 1987).

As this shift is found within the British-born second generation (from older to younger second generation individuals), the repertoire analysis reveals a considerable cultural lag and late stages of change in the community long after migration. This suggests that a reliance on totalizing categories such as 'second generation' or 'ethnolect' risks obscuring major distinctions within such categories. The repertoire analysis also highlights core conduits for positive valuation and retention of exogenous traits, in particular family domains, often excluded by common interview-based methods and a strong peer focus in the Western sociolinguistic tradition.

The findings support the notion of 'ethnolinguistic repertoire' (Eckert 2008b; Benor 2010; Newman 2010), rather than 'ethnolect' (Clyne 2000). However, many characterizations of repertoires involve broad claims of fluidity and individual agency. For instance, ethnolinguistic repertoire has been defined as 'a fluid set of linguistic resources that members of an ethnic group may use variably as they index their ethnic identities' (Benor 2010: 159), or as a 'pool of resources from which members of a speech community draw the linguistic tools they need' (Fought 2006: 21). Speakers are argued to 
'choose among this arsenal in accordance with the meanings they wish to convey' (Gumperz 1964: 138) or to activate 'different parts of their linguistic repertoires selectively in order to highlight particular aspects of their social identities (and to downplay others) in particular settings' (Doran 2004: 96). As in Newman (2010), the present study reveals the development of distinct types of hybrid repertoire under different conditions. Although all the individuals examined here combine elements from two broad dialect systems, British English and Indian English, some exhibit flexible and contextually variable use of these elements while others employ more invariant, fused lects (Auer 1999). The explanation provided moves beyond individual agency and explores the embedding of each individual within wider (and changing) social structures.

\section{FIELD SITE AND DATA COLLECTION}

At approximately four percent of the total population, South Asians represent the largest ethnic minority in the United Kingdom. 35 percent of this community lives in London, with a major concentration in West London. The small West London town in which data were collected for this study is Southall, widely recognized as the historic and contemporary hub of the West London Punjabi community. Today census estimates indicate that, out of a total population of approximately 70,000, 75 percent of Southall residents are of minority ethnic origin and at least 55 percent of South Asian heritage. Taking into account undocumented residents and a decade since census figures, we can estimate the Asian population at 60 percent and the overall ethnic minority proportion at 80 percent (Census 2001; DMAG 2006; Ealing JSNA 2010; see also Gillespie 1995 and Baumann 1996 for further ethnographic background on Southall).

The population of Southall includes both India-born and British-born residents. The India-born group migrated to the UK in adulthood and is continually renewed through ongoing migration. Their British-born offspring, the focus of this study, thus have a very diverse age range. The earliest British-born are now in their fifties, even sixties, but children being born now to more recent India-born migrants are also technically second generation. A third generation group is also growing in number now.

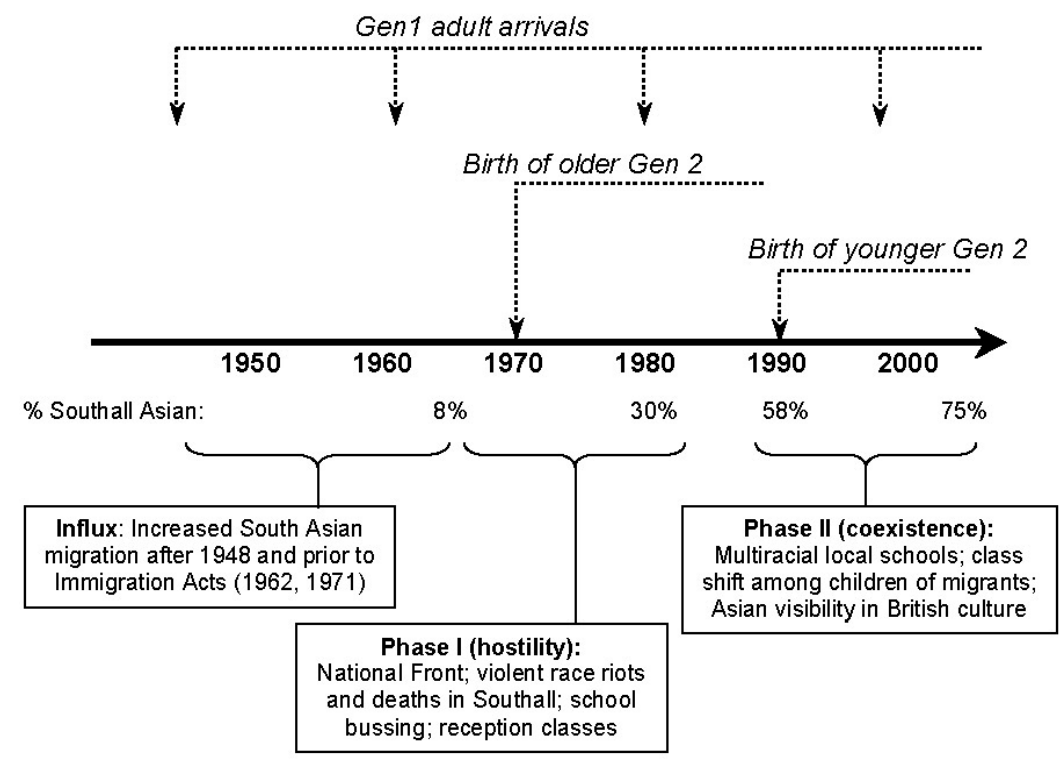

Figure 1: Demographic and sociopolitical changes over time in Southall 
Figure 1 outlines the recent history of Southall, highlighting two points important to the present analysis. First, over the course of 60 years, South Asians have shifted from being a minority to a majority demographic group in Southall. Second, and not unrelated, race relations have gone from overt hostility to cooperative coexistence. The older Britishborn group in our study grew up during the first phase, and the younger British-born group during the second.

In the post-war period (Phase I, late 1940s-late 1980s), the UK actively encouraged labor migration and permitted Commonwealth citizens to enter the UK without restriction. The South Asian and Caribbean populations grew substantially between 1948 and 1971, before a series of immigration acts were imposed. This increased migration was accompanied by growing political hostility (CARF 1981; Cashmore 1996; Oates 2002). Inter-ethnic tension took the form of national anti-immigration rhetoric (e.g. Enoch Powell's 1968 'Rivers of Blood' speech), political rallies by far-right parties, riots and race-related deaths, forced bussing of children implemented by parent groups in the white community, and language reception classes that separated non-European children from others.

These experiences formed an important collective history for older British Asians in our study and were alluded to repeatedly in their interviews, as in (1). ${ }^{\mathrm{i}}$

1. a. Anwar (older man, 41):

we had extreme tensions. we had big problems with them. whenever we would go to the park... they would hurl abuse at you and ... even you know like even spit at you. but um because we- you know we had our pride. there was absolutely no way we were going to be abused like this.

b. $\quad$ Naseem (older man, 48):

they'd come up and they'd attack us or they'd verbally abuse us and all that. so we had to be very very careful. i still remember those days it was quite frightening ... it's changed now due to race relations laws and everything. it's changed now a hell of a lot.

Although racial tension continued through the 1990s, the second phase of Asian history in Southall (Phase II, late 1980s-present) is characterized by a noticeable reduction of overt hostilities. It is no coincidence that this change in race relations corresponds to a shift in Southall demographics, such that the Commonwealth heritage population became the majority group (Oates 2002: 107; Meads 1983). Schools in the borough became dramatically more multi-racial, with the proportion of migrant ethnic origin students currently ranging from just under 50 percent to over 99 percent (Ealing JSNA 2010: 18). Today, many public signs in Southall are in English and Punjabi (even at the local pub) and the town's lively Punjabi atmosphere-bhangra music, Indian restaurants, clothing and jewellery shops - has become an institution in London. Children born and raised during the 1980s and 1990s were now growing up in a climate in which wider British society accepted an increasingly visible, legitimated, even celebrated, middle class British Asian culture (Herbert 2009), with music, comedians, media personalities, and politicians of Asian heritage.

In stark contrast to the older group, the younger British-born participants in our data rarely offered narratives of racial tension, instead describing experiences of being surrounded by an ethnically mixed, often Asian-dominant, peer group, as in (2). 
2. a. Sameer (younger man, 22):

it wasn't about racism nothing like that cos everyone knew each other in school... it was um mixture really but you know what there was- it was mainly indians like asian community and um somalians mostly. and couple of like um like jamaican. but british whites there was only like one or two most probably.

b. Deepti (younger woman, 32):

when i first started school you maybe had maybe a third of the class were indian and the rest were white. but by the time i'd left school i'd say out oflet me have a think. out of two hundred children in the year i remember there was one black kid one chinese kid and you'd be lucky to find maybe in a class of two hundred i don't know say about a quarter less than a quarter of that was white. they were all the majority were punjabis.

Ethnographic fieldwork was conducted by two researchers in the community over a period of nine months. Punjabi-speaking participants — almost all Sikh — were approached through a number of points of entry into the community, including local establishments (restaurants and shops), a local radio station, and friend-of-a-friend recommendations. The population sampling had two goals: to collect sociolinguistic interviews from a representative stratified sample and to collect a range of interactional data from selected individuals embedded within individual family networks.

The wider study collected data from first generation India-born residents and from two age groups of second generation British-born residents (see Figure 1). 74 participants were recorded, in most cases twice. The first recording was a sociolinguistic interview, lasting 1-2 hours. The second recording was also an interview, lasting 0.5-2 hours, but with the explicit goal of collecting detailed information on biography, networks, bilingualism, and cultural preferences (e.g. music, TV, cinema, leisure activities).

In addition to interviews, a subset of participants conducted self-recordings in diverse speech situations in the absence of either researcher. These recordings were made in order to capture a broader range of speech data from individuals representing different demographic segments. Willing participants from the first part of the study-two each from several demographic groups - were instructed simply to record in as many different speaking situations as possible. This method required slightly more awareness among these participants of the goals of the study, but details were avoided and participants were asked to record continuously for at least half an hour, preferably an hour, in order to reduce awareness of the self-recording situation.

A total of 120 hours of interview and self-recorded data were collected (using Sony MZ-RH1 and M-Audio Microtrack 24/96 recorders in interviews and Zoom H2 recorders with lapel microphones in self-recordings). Both interviewers had similar 'cosmopolitan' Indian English accents, helping to minimize distinct interviewer effects.

The present study focuses only on British-born individuals, divided into an older and a younger group, all second generation. ${ }^{\text {ii }}$ The study first reports on the sociolinguistic interviews of 24 participants: ten older generation British-born residents (born between 1960-1970 and raised during Phase I) and 14 younger generation British-born residents (born between 1980-1990 and raised during Phase II). The study then turns to the repertoire data recorded by four case study individuals, one each from four demographic sub-groups and supported by four 'parallel' individuals. 


\section{ANALYTIC METHOD}

The analysis is divided into two parts: Part I briefly presents a standard variationist analysis of one variable using sociolinguistic interview data. Part II embeds this variant within a cluster of variables and embeds the interview data within wider speech repertoires.

Part I examines retroflexion of $/ \mathrm{t} /$. Retroflexion is a contrastive consonantal series in most Indic languages that involves retraction of the tongue tip in the postalveolar region. Punjabi and Hindi have a contrast between retroflex and dental stops absent in British English, which only has an alveolar stop. Conversely, Punjabi and Hindi do not have an alveolar stop, and alveolar /t/ and /d/ are commonly replaced by retroflex / / and / / in varieties of Indian English (Masica 1993; Bhatia 1993; Pingali 2009).

The source languages show some variation in complete retroflexion of the tongue tip or simply retraction of the point of alveolar or postalveolar contact (Masica 1993: 94; Heselwood and McChrystal 2000: 57). Given this variation and the exclusive reliance on auditory analysis here, any degree of postalveolar retraction beyond British alveolar /t/ was included under 'retroflex' (cf. Alam 2007: 57 for a similar methodology). In order to check the reliability of the auditory coding, five percent of the data were coded blind by both coders, resulting in an inter-rater reliability of 90 percent.

Retroflex / / was selected for several reasons. First, it does not occur as a variant of /t/ in British English varieties and so is clearly an exogenous element, with a consistent indexical value linked to Asianness. Second, the feature is highly salient phonetically and socially in and beyond the community (Alam 2007; Lambert, Alam, and Stuart-Smith 2007; Rampton 1995; Chun 2007). In several interviews participants pointed to retroflexion as characteristic of either Indian English or Southall speech (see also example $9 \mathrm{~b}$ ). One family referred repeatedly to 'bu -bu ', an affectionately mocking term for Indian English that relies on a reduplicated retroflex as part of its enregisterment. This salience not only facilitates reliable auditory coding but also makes the feature more accessible to social adoption or avoidance (Trudgill 1986). Finally, the feature has been studied in previous work on British Asian communities, but only with respect to younger UK-born speakers; the present study thus adds to this picture by embedding the variant in a more complete picture of style range and change over time.

As the analysis in Part I does not constitute the heart of the present paper, all contexts of t-retroflexion - syllable-initial, word-medial, and word-final-are grouped together here and the focus is on a single external factor: gender. Further internal and external factors were coded but are analyzed in detail elsewhere (see Sharma and Sankaran forthcoming).

In Part II of the study, both the object and contexts of variation are expanded, in order to test the initial analysis. Retroflexion is examined alongside three other variants, and the interview data is examined alongside further speech settings.

There are a number of reasons for pursuing this expanded methodology. In a community with complex intersections with other communities (indeed one might argue in any community), it is never entirely clear how representative an interview sample of speech is. While interviews may capture a subset of natural speech styles (Wolfson 1976; Koven 2011), they do not routinely capture bidialectal or multilectal ability if it exists in a community, and can thus be inadequate for extrapolating the full social indexicality of a given set of variants (cf. Rickford and McNair-Knox 1994). In fact, the analysis will show that interviews cannot even be assumed to represent a similar (and therefore comparable) speech event or genre for all participants. The analysis will highlight further ways in which the inclusion of both a cluster of variants and a range of speaking 
situations leads to dramatically different generalizations about social meaning and change in the community.

The four variables examined in Part II are: / $t$ /, the FACE vowel, the GOAT vowel, and coda $/ 1 /$. The analysis divides variants of these four variables along a broad binary contrast of Indian English and British English (encompassing both standard and vernacular varieties of British English in London). The Indian-derived realizations are retroflex [ ], monophthongal [e], monophthongal [o], and clear coda [1], respectively. The British realizations include alveolar [t], diphthongal [e ], diphthongal [ə ], and dark coda [ ]; they also include more local London variants such as glottal stops [ ] in /t/ contexts, Cockney diphthongal variants, and l-vocalization. A binary classification is adopted here to explore how Asian and British allegiances are managed; naturally, a ternary or more complex set of macro-categories could reveal further structured variation. The binary split is also supported by meta-linguistic awareness of Indian and British English among interviewees, who were clearly conscious of operating at the intersection of two cultures and two language systems. Thus, although this study argues for diverse and localized forms of dialect hybridization, these local processes derive from speaker awareness of global dialect (and social) boundaries.

Part II presents four case study individuals in detail — an older man, an older woman, a younger man, and a younger woman. I also append comparable data for four parallel individuals in the Appendix as further support. In the discussion of results I address potential criticisms of this methodology. ${ }^{\text {iii }}$

Finally, as part of the explanation for findings in Part II, I briefly introduce a new network measure: a Diversity Index. In previous studies of ethnicity, network measures have focused on the proportion of ethnic or local ties in an individual's network (Gal 1978; Li, Milroy, and Pong 1992). However, in the present community, individuals had overwhelmingly Asian ties, so measures of network ethnicity were not sufficient. However, striking variation in the size and relative diversity of individuals' social worlds was apparent. For each participant we collected a list of acquaintances, friends, and relatives, along with information on frequency of interaction, domains of interaction (multiplexity), shared ties (density), dialect spoken by each contact, ethnicity of each contact, and a relative closeness ranking. Unlike Li, Milroy, and Pong (1992), in which a fixed number of ties was elicited, respondents determined the number of contacts they named.

Network size and diversity were measured through the use of a network metric that has not been used in sociolinguistics. A common diversity index has been widely used in other disciplines to measure the internal diversity of group membership in a given system, e.g. species diversity in biology (Simpson 1949) and demographic heterogeneity in sociology (Blau 1977). In the present work, I adapt this measure as follows: For a given participant, all the individuals they named as part of their network were grouped broadly into sub-groups based on the participant's own description, e.g. family, school friends, office colleagues, acquaintances at a volunteer site, college friends. The Diversity Index measures only two dimensions of this information: the number of individuals per group and the number of groups.

$$
\text { 3. Diversity Index: } \quad D=1-\sum_{i=1}^{n} p_{i}^{2}
$$

In the formula in (3), $p_{i}$ is the probability of affiliation to group $i$, and $n$ is the total number of groups (Gibbs and Martin 1962; Blau 1977; Degenne and Forsé 1999: 195). The index simply reflects the probability that a named individual in the network is a member of a particular sub-group. A higher value (closer to 1) indicates a higher level of 
diversity, in this case a robust distribution of individuals across a large number of subgroups in the network; a lower value (closer to 0) indicates lower levels of diversity, i.e. a skewed or limited number of sub-groups in the network. ${ }^{\text {iv }}$

\section{PART I: INTERVIEW RESULTS}

Figure 2 presents only the results for the external factor of gender in the use of retroflex / / among the older and younger British-Asians.

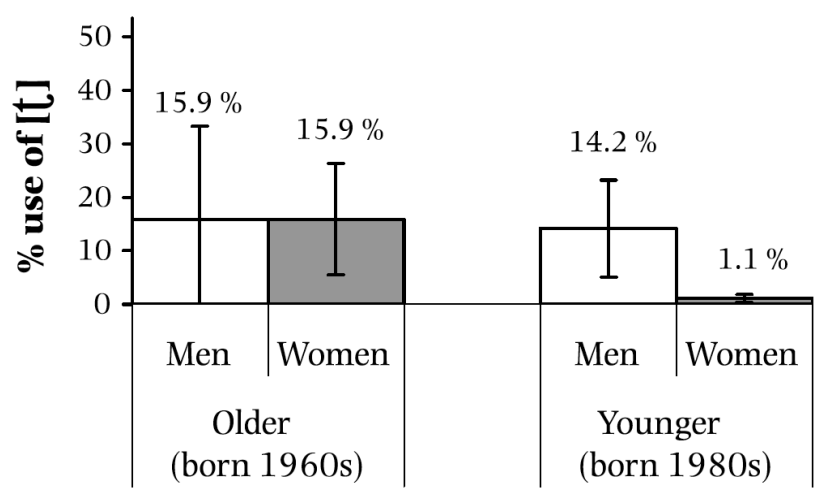

Figure 2: Gender differences in use of / / in interview data for older and younger Britishborn Asians

This distribution shows a clear shift over time in use of retroflexion in interview data. The older group shows no gendered difference, whereas the younger women show a dramatic decline in use. A Goldvarb analysis confirms this difference: Out of five external factors, gender was not selected as significant for the older group, but was overwhelmingly the strongest factor for the younger group (Goldvarb weights: men .77, women .18; range 59). I do not present the full result here as the only factor of interest for the present discussion is gender; see Sharma and Sankaran (forthcoming) for full details. $^{\mathrm{v}}$

This distribution is confirmed by the meta-linguistic commentary in (4), in which a younger man appears to be aware of greater standardness among girls.

4. Sameer (younger man, 22):

girls ain't really got like a Southall lingo. some girls have but not most of them. they like sound posh or something.

We can draw two tentative conclusions from this result: (i) use of retroflexion has nearly disappeared among younger women in the community; (ii) men across generations maintain a similar use of retroflexion. These two conclusions favor an interpretation in line with the common claim that 'in stable sociolinguistic stratification, men use a higher frequency of non-standard forms than women' (Labov 1990: 205; also Wolfram 1969; Trudgill 1972; Wolfram and Fasold 1974; Romaine 1984; Chambers 1995). Next, I evaluate this initial analysis using further data. 


\section{PART II: REPERTOIRE RESULTS}

The common practice of basing explanation on a single variable and on interview data has some limitations in terms of reliability and validity. Let us consider the conclusions drawn at the end of Part I as an example. First, we have not established whether interview data is sufficiently representative of the usage practices of each participant. Second, even if we assume that interview data represents a sufficient subset of usage, we have assumed that it represents the same sub-range for all participants (e.g. intermediate to formal style) and is therefore a reliable and comparable measure. Third, we concluded that men may have a similar social value for retroflexion, perhaps localness or vernacular meaning, which relies on the assumption that this one variable is representative of more general speech practices across age groups for men. Fourth, we have adopted a popular standardness or overt prestige account of why young women avoid use of what might be seen as a non-prestige variant with no explanation for why this only seems to occur one generation later. If all women orient to prestige variants, why do we not see older women also using less retroflexion? Fifth, because gender correlates with retroflex use, we have granted it a causal role, but in fact there is little evidence so far that gender is directly causal and not simply implicated by some other social process not yet examined. Finally, recalling the outline history for Southall, the gendered explanation provided has not been tied in any way to the details of what we know to be the lived, collective experience of members of the community at different historical phases. All of these issues weaken the validity of the initial interpretation of results in Part I.

The analysis that follows addresses these concerns, focusing on an expanded set of four variables and an expanded set of interactional contexts. The case studies consist of one sample individual from each British-born group: an older man, an older woman, a younger man, and a younger woman (see Table 1).

Table 1: Repertoire analysis case studies

\begin{tabular}{|c|c|c|c|c|}
\hline & GENDER & GENERATION & BORN AND RAISED & $\begin{array}{l}\text { AGE, YEAR OF BIRTH, } \\
\text { UPBRINGING }\end{array}$ \\
\hline Anwar & male & older & West London & $\begin{array}{c}41(1966) ; \\
\text { grew up during Phase I }\end{array}$ \\
\hline Simran & female & older & $\begin{array}{l}\text { Punjab, West } \\
\text { London }\end{array}$ & $\begin{array}{c}49(1960) ; \\
\text { grew up during Phase I }\end{array}$ \\
\hline Ravinder & male & younger & West London & $\begin{array}{l}20(1988) ; \\
\text { grew up during Phase II }\end{array}$ \\
\hline Namrita & female & younger & West London & $\begin{array}{c}28(1980) ; \\
\text { grew up during Phase II }\end{array}$ \\
\hline
\end{tabular}

The four charts that follow present rates for the four variables in each speaking context. The greater the magnitude of grey bars for a given context, the more the individual employed an Indian style in that situation; the greater the magnitude of white bars, the more they employed a British style. The 'British' columns are named for the standard British variants, as these are by far the most common, but as noted earlier the columns also incorporate some London vernacular variants. The number of contexts for each individual varies, as we could not strictly control how many contexts individuals ultimately provided recordings for. This gives rise to a few unfortunate gaps, discussed later, but for now the focus of the analysis is on the observable repertoire range for each 
individual (and their demographic 'twin' in the Appendix), not strictly the number of contexts provided. Finally, these repertoire charts should be read as a portrait of an individual's life-worlds. They do not constitute a formality continuum; 'family' and 'friends' are not ordered in terms of formality and even 'interview' is not found to correspond reliably to a more formal style for all individuals. They also do not represent communities of practice but broader abstractions, best thought of as a sample of interactional worlds or situations that individuals may accrue long-term exposure to.

\section{Older man: Anwar}

The first individual, Anwar, recorded in numerous settings. These are arrayed in Figure 3 from more Indian style, towards the left, to British style, towards the right.

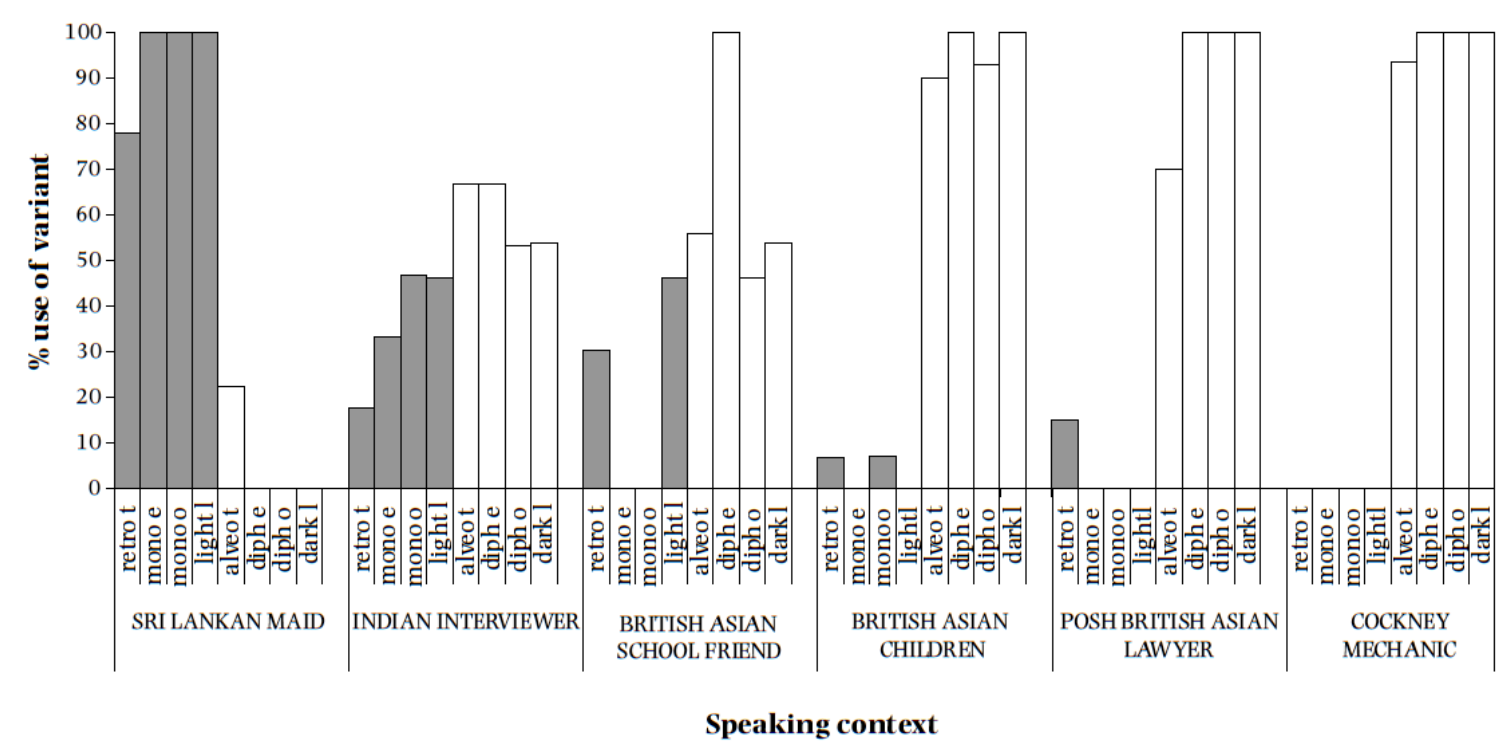

Figure 3: Use by older man (Anwar) of Indian and British variants across speaking situations ( $\square=$ Indian variants; $\square=$ British variants)

The most striking feature of Figure 3 is Anwar's dramatic differentiation of styles. He is able to employ entirely Indian English style or, alternatively, close to an entirely British English style. The representation in Figure 3 should not be interpreted as a binary continuum; Anwar in fact commands several styles, including a vernacular British style and a standard British style.

Figure A in the Appendix, which provides data for the four 'twin' cases as secondary support, shows that Sharan, the second self-recorder from this demographic, has a very similar, highly differentiated repertoire across interlocutors. The speech of both menand ethnographic observation suggests many men of this generation in Southallencompasses bidialectal ability in Indian and British English and a range of intermediate styles.

The three extracts of Anwar's speech in (5) illustrate the density of clustering of Indian variants, marked ' $\mathrm{I}$ ', in (5a) and standard British variants, marked ' $\mathrm{S}$ ', in (5b), as well as a more mixed style that includes both alongside London vernacular variants, marked ' $\mathrm{V}$ ', in $(5 \mathrm{c})$. A range of salient phonetic and lexical variants are highlighted in the extracts, not just the four quantified in the repertoire analysis. 
5. Anwar (older man, 41):

a. $\quad$ Addressing Indian interviewer:

but then one time I- my father y'know god rest his soul, he had a philosophy, $\begin{array}{ccccc}\text { I } & \text { I } & \text { I } & \text { I I I I } & \text { I } \\ \text { he goes to me 'yaar one of these days, this er food is going to become the }\end{array}$

I I I I I

u.k. national dish' and look what happened

b. Addressing white sales representative over the phone (researcher absent): the difficult two pieces we've bought them already we've got them but the- the $\mathrm{S}$

$S$ S S

$\mathrm{V} \mathrm{V}$

the main screen is something that is not just off the shelf it has to be made and $\mathrm{S} \mathrm{V} \quad \mathrm{S} \mathrm{V} \quad \mathrm{V}$ S $\mathrm{S}$ because i was told by national windscreen that you guys cut your own and make $\begin{array}{llllll}S & S & S & S & S\end{array}$ your own screens it's something that you- you'd be able to er assist us with

c. Addressing British Asian (different religious subgroup) school friend:
$\begin{array}{llllllll}\text { I I } & \text { V } & \text { V } & \text { V } & \text { V } & \text { S } & \text { V }\end{array}$ hor kiddan? [how are you doing?] what's going down man? everything cool? $\begin{array}{lllllllllllll}S & V & S & V & V & I & S & I & \text { IS I }\end{array}$ how's things at the yard? the old lady alright?

Older woman: Simran

The female self-recorder from the same generation has only two contexts, shown in Figure 4, so her data are not directly comparable. Nevertheless, based on the little data available, we can see a marked difference in her repertoire.

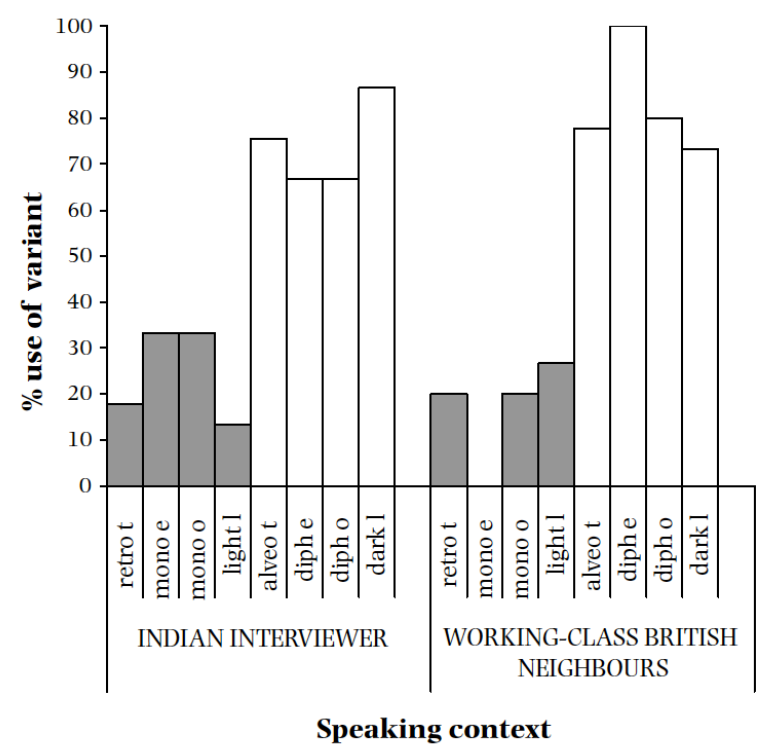

Figure 4: Indian and British variants across speaking situations (Simran: older woman)

Unlike the highly differentiated range that Anwar showed, Simran employs almost the same combination - mostly British with a few Indian variants - in both an interview with an Indian interlocutor and an informal interaction with English neighbors, with only 
a slight decrease in her use of Asian traits in the latter interaction. In the example in (6), Simran employs standard British variants alongside a few vernacular markers as well as Asian-influenced traits, much as she did in her interview.

6. Simran (older woman, 49, addressing white working class neighbors):

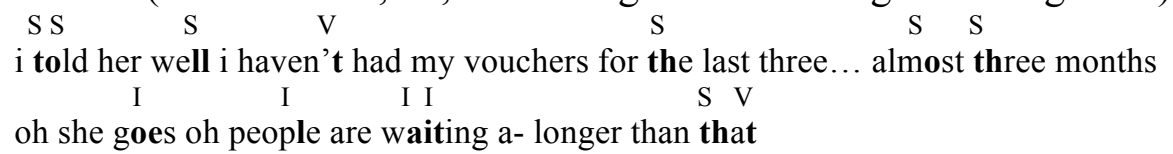

Figure A in the Appendix shows that self-recordings by Nina, the other woman of this age group, exhibit a similar maintenance of Indian traits across contexts.

Unfortunately no comparable recording with white interlocutors was provided by Nina, but ethnographic observation of her and other women of her age group confirmed maintenance of this style across contexts, including with a white co-worker in Nina's case. Note further that Nina does not shift when speaking to her daughter, in contrast to Anwar's shifts with his children.

In sum, whereas the older men have highly differentiated style repertoires, the older women appear to use a somewhat more fused and invariant style across contexts. Had we examined just the interview contexts in Figures 3 and 4, we would have incorrectly concluded, as in Part I, that there is no major difference between older men and women.

\section{Younger man: Ravinder}

Next, I turn to the younger generation of British-born Asians in Southall, again focusing on one man and one woman as case studies with 'twin' supporting cases.

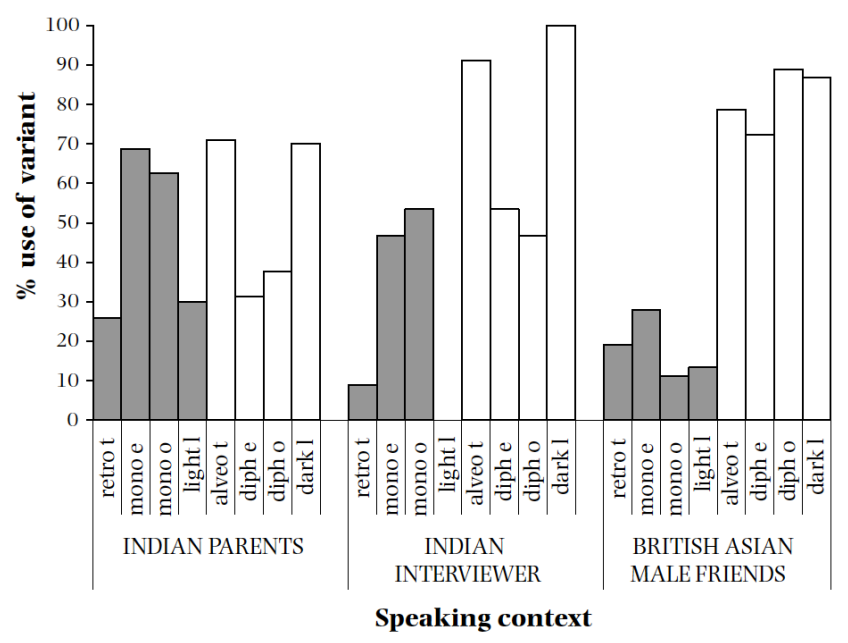

Figure 5: Indian and British variants across speaking situations (Ravinder: younger man)

Ravinder provided three contexts, shown in Figure 5. Although he shows some variation from Indian to British styles, he uses no completely Indian or completely British style. To this extent, he is more comparable to Simran than Anwar. (Once again, Figure A shows that Anand also has no wholesale code alternation by context. His use of retroflex / / in particular shows almost no variation.) The lack of self-recordings with white British interlocutors is again an unfortunate gap, precluding a direct comparison to Anwar. Nevertheless, our observations of young men in the community and even in popular 
culture (e.g. Asian youth speech in the sketch comedy show Goodness Gracious Me) supports the use of a relatively invariant hybrid style used across communicative contexts. Indeed, Anand comments on his own use of Punjabi variants with non-Asian friends in (7).

7. Anand (younger man, 23):

when i'm with my punjabi peers... every now and then a word or two in punjabi will come in, but we intend that to happen. it's intentional. and then there's other times when it happens unintentionally with um my english friends... i'll speak an english word but it'll come out with an indian accent.

Ravinder has marginally higher levels of Indian variants in his home interactions as compared to other younger men we interviewed, possibly due to his having spent five years in India living with his grandmother. Despite this, his range is not nearly as differentiated as Anwar's. The repertoires of these younger British Asian men in Southall appear more like the repertoires of older British Asian women than men, in their use of a relatively fused lect across settings.

\section{Younger woman: Namrita}

Finally, let us consider a younger British Asian woman. Namrita provided four contexts, presented in Figure 6.

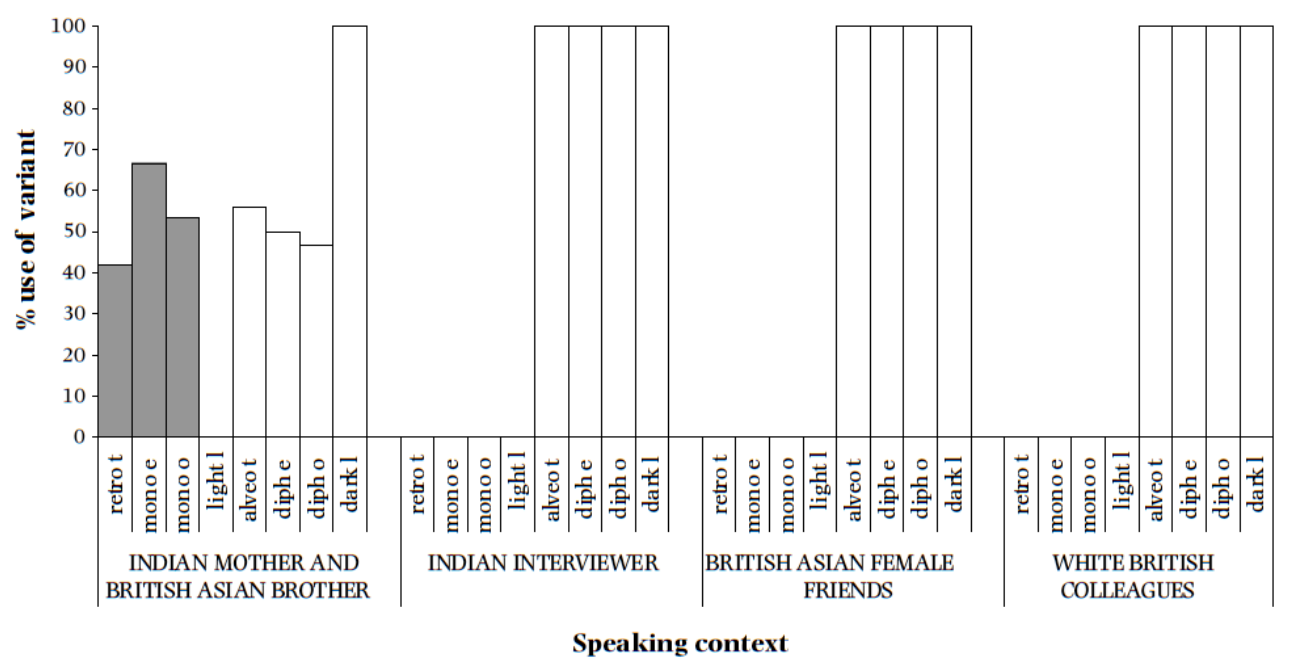

Figure 6: Use by younger woman (Namrita) of Indian and British variants across speaking situations $(\square=$ Indian variants; $\square=$ British variants)

We can see immediately that her repertoire involves sharp differentiation. In three settings she shows no use at all of Indian variants; recall that this pattern in interview data was the basis of concluding in Part I that younger women no longer use Indian variants such as retroflexion. However, her home recordings revealed surprisingly regular use of Indian variants. The examples in (8) illustrate her total lack of Indian style in interview speech, which consists of highly standard, even posh, British variants, and her noticeably mixed style at home. 
8. Namrita (younger woman):

a. $\quad \frac{\text { Addressing Indian interviewer: }}{\mathrm{S} S \mathrm{~S} S \mathrm{~S}} \mathrm{~S} \quad \mathrm{~S}$ S $\mathrm{S} S$

i wanted to go into media i wanted to go into acting

b. Addressing her younger brother (whose speech resembles Ravinder's fused style):

but then i didn't have time... and hotels and everything

The other self-recorder from this demographic, Guddi (see Appendix, Figure A), is remarkably similar to Namrita in adopting an entirely British style for community interface contexts and reserving a notably Indianized style for more personal contexts.

The extracts in (9) show that several younger women explicitly volunteered that they speak differently at home. All three women had almost no use of retroflexion in their interviews $(0-2 \%)$.

9. a. Namrita (age 28):

i won't speak to my mum or dad in the- in the accent i'm speaking to you in now but $i$ will $i-i$ will put on an indian accent when i speak english to them which is kind of very funny. it comes very very naturally.

b. $\quad$ Preeti (age 23):

i hate it but i know i do [ ] and [ ] with my parents.

c. $\quad$ Rita (age 22):

i talk to basma like um i'm a freshie i talk to my mum like i'm a freshie... i become a bit more indian.

Although older men exhibit wholesale bidialectal alternation and younger women only range from a British style to a fused style (similar to that of younger men), the two groups are similar to the extent that they both show sharp style shifts by context.

In sum, the four case studies present us with an intriguing picture: It is older men and younger women who use a highly differentiated repertoire, and older women and younger men who have a more fused and invariant repertoire.

Before turning to an explanation for these findings, I briefly address three potential critiques of this approach: generalizability of patterns, comparability of contexts, and reliability of responses.

The first criticism may be that, in order to perform the detailed repertoire analysis the analytic lens has been focused on individual cases, whose behavior may not be generalizable. The 'twin' individuals for each of the four demographic groups in Figure A have been appended to permit a degree of generalization (although they do remind us that every individual and every variable is different). Ethnographic observation and metalinguistic commentaries have also served to bolster generalizations.

A second criticism is non-comparability of contexts, in particular the range and choice (rather than total number) of contexts recorded. The data are admittedly far from complete; for instance, interactions with non-Asians were not recorded for younger men, who often have very few such interactions. A full set of same- and other-gender recordings for younger individuals would also be extremely informative. Ethnographic field observation has been useful in places, for instance, in noting the lack of wholesale dialect alternation among younger men. Style range within a single interaction can also bolster this claim: Anwar shows dramatic style shifts within a single narrative in his sociolinguistic interview, as do other older British-born men; in over 20 interviews with younger men I was unable to find any such range of style-shifting within interviews or narratives. 
Finally, one might ask how reliably self-recordings reflect 'natural' speech styles, given the potential for performing artificially for the recorder. The strongest indication that the data are not distorted by such effects is that in none of the 38 self-recordings gathered do we see any remark from an interlocutor on the peculiar behavior or style of speech of the self-recording individual. The self-recorder is consistently accepted as conforming to their usual style of interaction, suggesting no marked divergence from the style they might regularly employ.

\section{DISCUSSION}

Two broad types of repertoire are observable among British-born Asians in Southall: flexible and highly differentiated (used by older men and younger women), and more fused and invariant (used by older women and younger men). In this section I first discuss the implications of this descriptive generalization for sociolinguistic research, and then briefly present a possible explanation for the pattern.

Contextualizing the interview data in Figures 3-6 within repertoires has revealed a number of limitations of the method and analysis in Part I. The first conclusion tentatively proposed in Part I was that younger women avoid use of the Asian retroflex variant. However, Namrita's (and Guddi's) repertoires showed an Asianized style reserved for home interactions, a context which appears to be a core conduit for retention of traits for both women. (In Guddi's case we also see an Asian style for interaction with British Asian male friends.) Standardness in interviews is therefore not indicative of a rejection, total absence, or non-acquisition of Indian style. Namrita's overall rate of use may indeed be lower when averaged over all her interactions as compared to other groups, so conformity to an overt prestige norm may not be entirely irrelevant. However, she does not reserve Asian traits merely for vari-directional voicing, mockery, or other distanced and 'othered' uses; she shows consistently positive, unidirectional alignments with these variants in a central domain of her life.

The second tentative conclusion in Part I was that men are similar across generations in using more retroflexion. Once again, the repertoire analysis showed this to be a misrepresentation, as major differences are found between older men, who have highly variable repertoires, and younger men, who have less differentiated repertoires. Overall rates of use might be comparable but the allocation of uses is markedly different, indicating distinct social functions.

The analysis in Part II has further shown that interview speech does not consistently occupy the same position in each speakers' repertoire; some speakers employ a hybrid style in their interviews while others produce their most British style. This warns us that interviews may not always be a reliable indicator of the same style or style range for a set of individuals.

Finally, it is worth noting that the repertoire analysis also resists a simple accommodation or audience design explanation, as such an account cannot explain why some individuals vary so much less than others in response to similar interlocutors.

So far we have no explanation for why two types of repertoire develop, nor for why a gendered reversal occurs in their distribution in the community. What could account for these findings?

The observed reversal - differentiated for older men and younger women and fused for older women and younger men-shows clearly that neither age nor gender is directly correlated with repertoire type. Even if we adopt complex categories such as 'older men' an explanation is not immediately apparent. 
As noted earlier, ethnicity or 'Asianness' of networks does not vary greatly, as most individuals have very Asian networks. However, the relative range of social worlds they participate in does vary considerably. Table 2 reports the Network Diversity Index calculated for each individual. The values reflect precisely the same odd gender pairing as the repertoires. The older man and younger woman interact regularly with much more diverse groups within their networks, and the older woman and younger man have much less diverse networks. To understand why this is, we need to return to the historical phases introduced earlier.

Table 2: Network Diversity Index by gender and generation

\begin{tabular}{lcccc}
\hline \hline & GENDER & GENERATION & $\begin{array}{c}\text { NETWORK } \\
\text { DIVERSITY INDEX }\end{array}$ & REPERTOIRE TYPE \\
\hline Anwar & male & older & .81 & differentiated \\
Simran & female & older & .58 & fused \\
Ravinder & male & younger & .65 & fused \\
Namrita & female & younger & .82 & differentiated \\
\hline \hline
\end{tabular}

Older men in this community grew up during Phase I, in a minority community. They frequently went into their father's businesses, thereby maintaining strong transnational ties to India through family and business travel. Yet they also experienced pervasive hostility and frequently needed to pass as entirely British. Furthermore, their generation was the first to assert its right to be British by becoming deeply political; several of our older male participants were involved in either local British council politics or activist groups. Older men thus accumulated deep exposure to both Indian and British communities, which may relate to their complex repertoire range.

Older women, by contrast, tended to be very community- and family-bound. Despite being schooled in Britain, their life choices-e.g. further education, employment, choice of spouse-were often strongly determined by their parents. For instance, one older woman reported that because her arranged marriage ended within a year due to domestic violence, she was made to care for her ailing father for the next 30 years. Neither an older man nor a younger woman in the community would be likely to experience this level of parental control. Many of the middle-aged women in this study thus had much narrower life-worlds than their male counterparts.

One exception further supports this analysis. Nimmi, an older British Asian woman, showed a much more differentiated style repertoire than the majority of women of her age group. She even comments on this in her interview, in (10):

10. Nimmi (older woman, 43):

when $\mathrm{i}$ ' $m$ in india my english is different. $\mathrm{i}$ know that because $\mathrm{i}-\mathrm{i}$ bring on their accent and there'll be certain dialect that they use that I wouldn't certainly use here.

However, Nimmi is more middle class and has active transnational family and business ties in India as well as being deeply integrated into British networks. Thus, in terms of network diversity and life-worlds, she much more closely resembles men of her generation and her repertoire appears to reflect this.

The younger generation grew up during Phase II, in a majority Asian neighborhood. Younger men grew up in large British Asian friendship groups and strongly favored local employment and entertainment. Despite little direct contact with India—some had only 
visited once - they consistently orient positively towards idealized 'traditional' Punjabi cultural practices, as in (11).

11. a. Vikas (younger man, 23):

$\mathrm{i}$ think the immigrant way heh i might be biased to it but i actually think it's the best way. because um you end up having more support in an extended family than you would in a nuclear family... like i'm quite a traditionalist in the sense that whilst i fully expect my wife to be out there you know my girlfriend's in medical school too. she's studying neuroscience and whilst $i$ fully expect her and i would encourage her at every turn to do what she wants to do i would still expect her to have a motherly role. so you know um and one of the roles of the mother is to you know cook for the family to do motherly things like my mum does. um so i think maybe there's a danger of being too post-modern and saying that nah you know women don't have to do any of that role. maybe it's too i don't know you see th- i'm in danger of sounding like a misogynist.

b. Sameer (younger man, 22):

Sameer: if it's arranged marriage you have to date the girl to know what she's like. but you just get straight bang straight into it just get married an arranged marriage that's just being stupid. i'm not going to likethat's just being plain stupid.

DS: but you wouldn't mind being introduced to-

Sameer: yea i wouldn't mind. ... i'd say bring all of them. line them up. heh heh.

By contrast, younger women expressed far more ambivalent orientations to traditional cultural norms, as in (12).

12. a. Deepti (younger woman, 32):

LS: what do think of the whole extended family thing? you know the mother-in-law, the daughter-in-law (xxx)

Deepti: oh my god horrific, $i$ think

LS: $\quad$... so do you think it doesn't really work anymore?

Deepti: no, because i think it holds you back from being your own person, because you're trying to fit in with everybody else, so i think everyone should be free to just live their lives as they need to rather than feeling you know judged.

b. Rita (younger woman, 20):

when children come into the picture one of them does have- will have to stay behind, will have to look after the children and who is that one person, the wife. although when i get married it's not going to be me. heheh. it's going to be fifty-fifty babe heheh. oh yea so that's just the way it is... there's that theory that um women er women are emotional and men are rational thinkers. i don't believe that theory... i still think you know what? yes the world has modernized into a fantastic place. technology god knows what has you know evolved yet a girl will still be a girl. ... there's still inequality in this world. and even when my kids are born there will still be inequality. 
c. Preeti (younger woman, 23):

DS: why do you say boys are more into traditional culture?

Preeti: well it works for them. doesn't it?

Perhaps in response to this ambivalence, younger women crossed the boundaries of the community more, pursuing higher education more extensively than the boys and finding employment both outside and within the community. Older British Asian women may share this ambivalence, but the younger women are freer to pursue opportunities beyond the community (cf. Gal 1978). Like the older men, but for very different reasons, younger women have a deep investment in participating fully in the two different communities, British and Asian. It is important to note that they do not reject Punjabi culture; for instance, the average rate of maintenance of Punjabi showed no significant difference for younger men and women. Rather, they seek to expand their life worlds to maximize opportunities in a way that the younger men feel less need to and the older women have less ability to.

It is no accident that older men and younger women are the groups that develop more diverse networks. The description of the older generation above reflects gender roles typical of LMC traditional societies, with women more insulated within the community and men mediating the interfaces (Haeri 1987; Abdel-Jawad 1987; Labov 1982; Bakir 1986; Li, Milroy, and Pong 1992). The pattern described for the younger generation is typical of Western working class and LMC societies, with men more insulated within the community and women mediating the interfaces (Milroy 1987, Nichols 1979).

The apparent correspondence between repertoire type and network diversity in Table 2 suggests that diverse dialect repertoires develop in those demographic sub-groups who have developed more diverse networks, which in effect represent exposure and opportunity to fully develop distinct linguistic styles (LePage and Tabouret-Keller 1985).

Bearing in mind that all groups involved in this transformation are born and raised in Britain, dialect repertoire analysis has revealed an underlying cultural lag of one generation in social structure, with gradual but systematic social change moving towards norms typical of the dominant society.

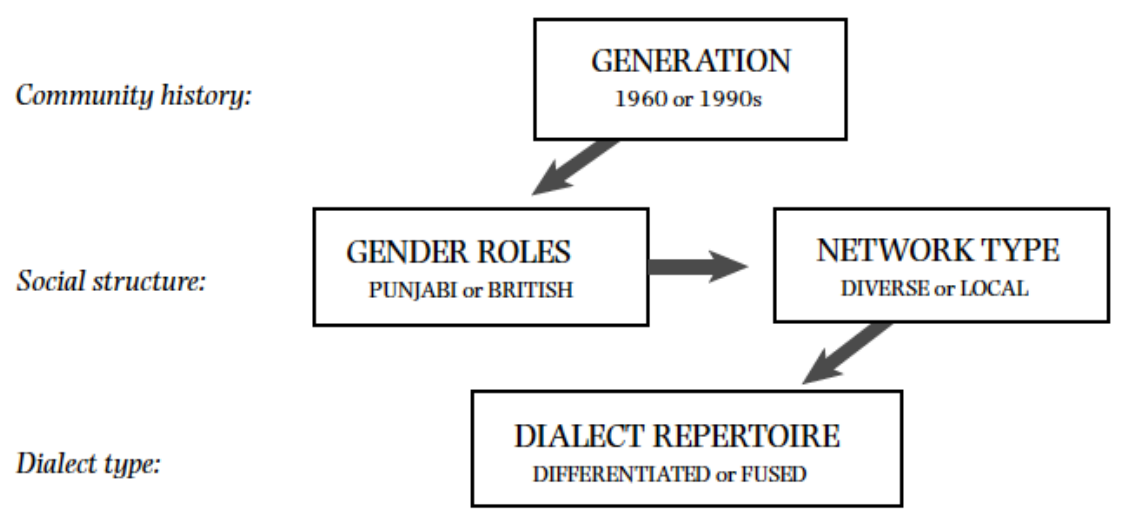

Figure 7: Factors in the development of different repertoire types

In contrast to the initial analysis based on female orientation to overt prestige, the integrated repertoire analysis — summarized in Figure 7-shows that gender is a 
secondary component of a more broad shift from traditional Punjabi to Western urban social roles across generations. This in turn leads to stark differences in relative network diversity, which ultimately corresponds to different dialect repertoire types. By starting with the final element - dialect repertoire - we are able to bring to light a subtle and slow transformation in the structure of the community, from the earliest to the most recent British-born group. The analysis is also more robust than the preliminary analysis in Part I in corresponding far more closely to independent historical facts about the Southall Asian community.

\section{CONCLUSIONS}

This study has proposed both empirical and methodological directions in the study of dialect variation in urban contact settings.

The most general empirical finding is that individual dialect repertoires can reveal evidence of systematic changes in social structure. In the present case, they reveal a retention of traditionally-based Punjabi social structures for a whole British-born generation. In addition, the reversal in dialect repertoire types by gender, from the older to the younger generation, is noteworthy. Drawing on studies that treat gendered variation as based in political economy rather than essentialized psychological predispositions (e.g. Gal 1978; Nichols 1979; Eckert 1989; Escure 1991), Chambers (1995: 125-6) concludes that 'in societies where gender roles are sharply differentiated such that one gender has wider social contacts and greater geographical range, the speech of the less circumscribed gender will include more variants of the contiguous social groups.' The present study corroborates a version of this claim. The Diversity Index showed 'wider social contacts' for men in the older group and for women in the younger, refuting any essentialist gendered account. Repertoire differences show variation to be gender-linked but ultimately not gender-based. Younger women are not being more standard simply by virtue of being women; they are being more strategically 'compartmentalized' in their variation, managing multiple community membership as part of a shift from traditional to Western urban LMC roles.

A further empirical contribution is evidence of the strong influence of home contexts as a conduit for dialect acquisition in communities with non-western social structures. This detail, easily missed under standard interview-based methodologies (as in Part I), questions the universality of a parent-peer opposition and strong peer orientation in sociolinguistic theory. It minimally requires greater attention to home domains for the retention and social re-indexing of exogenous traits (Hazen 2002; Stanford 2008; Khattab 2009; Sharma and Sankaran forthcoming).

A final empirical contribution to recent studies of second generation groups (Cf. Blake 2010) is the proposal that 'second generation' is not a unitary category. When continually replenished through ongoing migration, the second generation can be internally heterogeneous, encompassing several stages of social and linguistic change. All research on British Asians to date has sampled younger individuals as representative of the second generation (e.g. Heselwood and McChrystal 2000; Khan 2003; Hirson and Sohail 2007; Evans, Mistry, and Moreiras 2007; Lambert, Alam, and Stuart-Smith 2007; Kirkham 2011). This study has shown that older second generation British Asians constitute a crucial intermediate stage, acting as bicultural and multilectal brokers and through their practices re-inscribing linguistic markers with new social indexical values, meanings that then become available for continued use by younger generations. The multiple modes of combining Punjabi and British features further problematize the idea 
of a single 'ethnolect' in such communities (Cf. Eckert 2008b; Benor 2010; Hall-Lew and Starr 2010; Hinrichs 2010; Newman 2010).

The study has also made several methodological proposals. The main proposal has been the analysis of contextual variation in the form of repertoire 'portraits'. This mesolevel is finer than macro-social categories such as class or gender, but broader than micro-social variation at the level of discourse. Types of repertoire were found, through the Diversity Index, to correspond to the relative complexity of social worlds that individuals develop, and thus represent a useful level of analysis to understand ongoing social change.

The repertoire approach has also shown how seriously standard quantitative methodologies can misrepresent the ability and range of individuals, as well as the social indexicality of given dialect traits. The behavior of a variant and its correspondence to social factors appeared dramatically different in the single-feature, interview-based analysis and in the multi-feature, repertoire-based analysis. The latter approach may be more robust for extrapolating social meaning, and consequently for understanding ongoing change in (or persistence of) particular speech practices. 


\section{REFERENCES}

Abdel-Jawad, Hassan R. 1987. Cross-dialectal variation in Arabic: competing prestigious forms. Language in Society 16: 359-368.

Agha, Asif. 2007. Language and social relations. Cambridge: Cambridge University Press.

Alam, Farhana. 2007. Language and identity in 'Glaswasian' adolescents. MLitt Dissertation. University of Glasgow.

Auer, Peter. 1999. From codeswitching via language mixing to fused lects: Toward a dynamic typology of bilingual speech. Journal of Bilingualism 34: 309-332.

Bakir, Murtadha. 1986. Sex differences in the approximation to Standard Arabic: A case study. Anthropological Linguistics 28: 3-9.

Baumann, Gerd. 1996. Contesting Culture: Discourses of Identity in Multi-ethnic London. Cambridge: Cambridge University Press.

Benor, Sarah Bunin. 2010. Ethnolinguistic repertoire: Shifting the analytic focus in language and ethnicity. Journal of Sociolinguistics 14 (2): 159-183.

Bhatia, T. K. 1993. Punjabi: A cognitive-descriptive grammar. London: Routledge.

Blake, Renee (ed.). 2010. Special Issue on 'Social and Linguistic State of 2nd Generation Americans', English Today 26 (3).

Blau, Peter. 1977. Inequality and Heterogeneity. New York: The Free Press.

CARF (Campaign against Racism and Fascism). 1981. Southall: The Birth of a Black Community. London: Institute of Race Relations.

Cashmore, Ernest. 1996. A Dictionary of Race and Ethnic Relations. London: Routledge.

Census 2001. United Kingdom Office for National Statistics, accessed on 3 November 2010 from www.statistics.gov.uk.

Chambers, Jack. 1995. Sociolinguistic Theory. Oxford: Blackwell.

Chun, Elaine. 2007. The Meaning of Mocking: Stylizations of Asians and Preps at a U.S. High School. Unpublished PhD dissertation. University of Texas, Austin.

Clyne, Michael. 2000. Lingua franca and ethnolects in Europe and beyond. Sociolinguistica 14: 83-89.

Coupland, Nik. 2007. Style: Language Variation and Identity. Cambridge: Cambridge University Press.

Degenne, Alain, and Michel Forsé. 1999. Introducing Social Networks. London: Sage.

DMAG (Data Management and Analysis Group, Greater London Authority) Briefing, 2006. Accessed on 3 November 2010 from www.london.gov.uk.

Doran, Meredith. 2004. Negotiating between 'Bourge' and 'Racaille': Verlan as Youth Identity Practice in Suburban Paris. In Aneta Pavlenko and Adrian Blackledge (eds.) Negotiation of Identities in Multilingual Contexts. Clevedon: Multilingual Matters. 93-124.

Ealing JSNA (Joint Strategic Needs Assessment) report. 2010. Accessed on 3 November 2010 from: http://www.ealingpct.nhs.uk/Publications/needs-assessment.asp

Eckert, Penelope. 1989. The whole woman: Sex and gender differences in variation. Language Variation and Change 1, 245-268.

Eckert, Penelope. 2005. Variation, convention, and social meaning. Paper presented at the Annual Meeting of the Linguistic Society of America, Oakland, CA.

Eckert, Penelope. 2008a. Variation and the indexical field. Journal of Sociolinguistics 12: 453-76.

Eckert, Penelope. 2008b. Where do ethnolects stop? International Journal of Bilingualism 12 (1): 25-42. 
Escure, Genevieve. 1991. Gender roles and linguistic variation in the Belizean Creole community. In Jenny Cheshire (ed.) English Around the World: Sociolinguistic Perspectives, Cambridge: Cambridge University Press. 595-608.

Evans, Bronwen, Ajay Mistry, and Caroline Moreiras. 2007. An acoustic study of firstand second-generation Gujarati immigrants in Wembley: Evidence for accent convergence? In Jürgen Trouvain and William Barry (eds.) Proceedings of the $16^{\text {th }}$ International Congress of Phonetics Sciences (ICPhS), Saarbrücken. 1741-44.

Fought, Carmen. 2006. Language and Ethnicity. Cambridge: Cambridge University Press.

Gal, Susan. 1978. Peasant men can't get wives: language change and sex roles in a bilingual community. Language in Society $7: 1-16$.

Gibbs, Jack P., and William T. Martin. 1962. Urbanization, technology and the division of labor. American Sociological Review 27: 667-77.

Gillespie, Marie. 1995. Television, Ethnicity, and Cultural Change. London: Routledge.

Gumperz, John, 1964. Linguistic and social interaction in two communities. American Anthropologist 66: 137-154.

Haeri, Niloofar. 1987. Male/female differences in speech: an alternative interpretation, In K. Denning, Sharon Inkelas, Faye McNair-Knox and John R. Rickford (eds.) Variation in language, $N W A V X V$, Stanford University, California.

Hall-Lew, Lauren, and Rebecca Starr. 2010. Beyond the 2nd Generation: English use among Chinese Americans in the San Francisco Bay Area. English Today 26 (3): $12-19$.

Hazen, Kirk. 2002. The family. In J. K. Chambers, Peter Trudgill, and Natalie SchillingEstes (eds.) The Handbook of Language Variation and Change. Oxford: Blackwell. 500-526.

Herbert, Joanna. 2009. Oral histories of the Ugandan Asians in Britain: gendered identities in the diaspora. Contemporary South Asia 17 (1): 21-32.

Heselwood, Barry, and Louise McChrystal. 2000. Gender, accent featured and voicing in Panjabi-English bilingual children. Leeds Working Papers in Linguistics and Phonetics 8: 45-70.

Hinrichs, Lars. 2010. 'Retention' of Jamaican phonetic features in Caribbean Canadians in Toronto. Paper presented at Workshop on Dialect and Social Change in Urban Diasporic Communities, Queen Mary University of London, July 2010.

Hirson, Allen, and Nabiah Sohail. 2007. Variability of rhotics in Punjabi-English bilinguals. In Jürgen Trouvain and William Barry (eds.) Proceedings ICPhS XVI, Saarbrücken. 1501-4.

Khan, Arfaan. 2003. Reading revisited: dialect levelling within a multi-ethnic British community. MA dissertation. University of Reading.

Khattab, Ghada. 2009. Phonetic accommodation in children's code-switching. In Barbara E. Bullock and Almeida Jacqueline Toribio (eds.) The Cambridge Handbook of Linguistic Code-switching. Cambridge: Cambridge University Press. 142-160.

Kirkham, Sam. Forthcoming (2011). The acoustics of coronal stops in British Asian English. In Proceedings of the $17^{\text {th }}$ International Congress of Phonetics Sciences (ICPhS), Hong Kong, China.

Koven, Michele. 2011. Comparing stories told in sociolinguistic interviews and spontaneous conversation. Language in Society 40: 75-89.

Labov, William. 1982. Building on empirical foundations. In Winfred P. Lehmann and Yakov Malkiel (eds.) Perspectives on Historical Linguistics. Amsterdam: John Benjamins. 79-92. 
Labov, William. 1990. The intersection of sex and social class in the course of linguistic change. Language Variation and Change 2: 205-254.

Lambert, Kirsten, Farhana Alam, and Stuart-Smith, Jane. 2007. Investigating British Asian accents: Studies from Glasgow. In Jürgen Trouvain and William Barry (eds.) Proceedings of the $16^{\text {th }}$ International Congress of Phonetics Sciences (ICPhS), Saarbrücken. 1509-11.

Le Page, Robert, and Andrée Tabouret-Keller. 1985. Acts of Identity: Creole-based approaches to language and ethnicity. Cambridge: Cambridge University Press.

Li Wei, Lesley Milroy, and S. C. Pong. 1992. A two-step sociolinguistic analysis of codeswitching and language choice. International Journal of Applied Linguistics 2 (1): 63-86.

Masica, Colin. 1993. The Indo-Aryan Languages. Cambridge: Cambridge University Press.

Meads, R. J. 1983. Southall 830-1982. London: Merlin.

Milroy, Lesley. 1987. Language and Social Networks, $2^{\text {nd }}$ edition. Oxford: WileyBlackwell.

Newman, Michael. 2010. Focusing, implicational scaling, and the dialect status of New York Latino English. Journal of Sociolinguistics 14 (2): 207-239.

Nichols, Patricia. 1979. Black women in the rural South: conservative and innovative. In Betty Dubois and Isabel Crouch (eds.) The Sociology of the Languages of American Women. San Antonio: Trinity University.

Oates, Jonathan. 2002. Southall and Hanwell. London: The History Press Ltd.

Pingali Sailaja. 2009. Indian English. Edinburgh: Edinburgh University Press.

Podesva, Robert. 2007. Phonation type as a stylistic variable: The use of falsetto in constructing a persona. Journal of Sociolinguistics 11 (4): 478-504.

Rampton, Ben. 1995. Crossing: Language and Ethnicity among Adolescents. London: Longman.

Rampton, Ben, and D. Sharma. 2010. Lectal focusing in interaction. Presentation at Sociolinguistics Symposium, Southampton, September 2010.

Rickford, John, and Faye McNair-Knox. 1994. Addressee- and topic- influenced style shift: A quantitative sociolinguistic study. In Douglas Biber and Edward Finegan (eds.) Sociolinguistic Perspectives on Register. New York: Oxford University Press. 235-276.

Romaine, Suzanne. 1984. The Language of Children and Adolescents: The Acquisition of Communicative Competence. Oxford: Blackwell.

Sharma, Devyani, and Lavanya Sankaran. forthcoming. Cognitive and social factors in dialect shift: Gradual change in British Asian speech. Language Variation and Change.

Simpson, Edward H. 1949. Measurement of diversity. Nature 163: 688.

Stanford, James. 2008. Child dialect acquisition: New perspectives on parent/peer influence. Journal of Sociolinguistics 12 (5): 567-596.

Trudgill, Peter. 1972. Sex, covert prestige, and linguistic change in the urban British English of Norwich. Language in Society 1: 179-96.

Trudgill, Peter. 1986. Dialects in Contact. New York: Blackwell.

Wolfson, Nessa. 1976. Speech events and natural speech: some implications for sociolinguistic methodology. Language in Society 5: 189-209.

Wolfram, Walt. 1969. A Sociolinguistic Description of Detroit Negro Speech. Washington, DC: Center for Applied Linguistics.

Wolfram, Walt, and Ralph Fasold. 1974. The Study of Social Dialects in American English. Englewood Cliffs, NJ: Prentice Hall. 
Address correspondence to:

Devyani Sharma

Department of Linguistics

Queen Mary, University of London

Mile End Road

London E1 4NS

United Kingdom

Email: d.sharma@qmul.ac.uk 

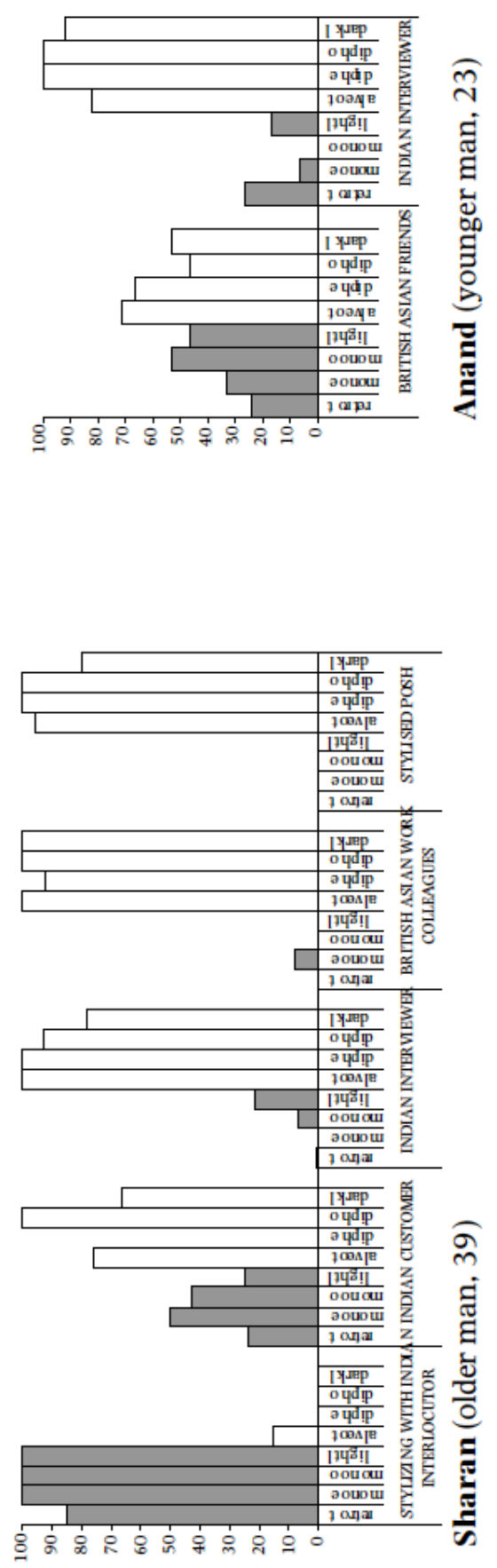

pUе!.лек уо әsn \%
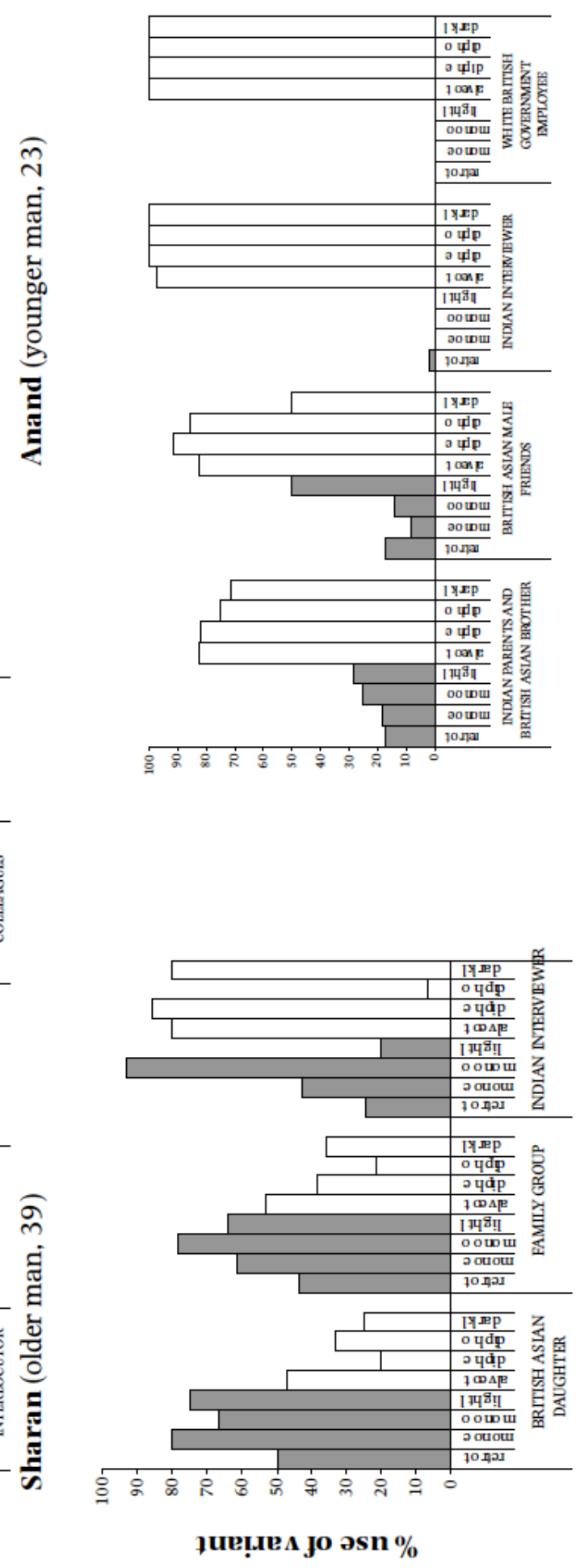

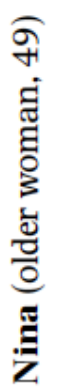

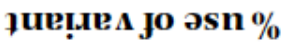

Figure A: Self-recorded repertoires for four supporting case studies 


\section{NOTES}

Acknowledgement: I gratefully acknowledge funding provided by the United Kingdom ESRC (Economic and Social Research Council, Standard Grant RES-06223-06-04), without which this research would not have been possible. I am enormously indebted to Lavanya Sankaran for her contributions in fieldwork and data processing. Pam Knight, James Hawkey, Veronique Lacoste, John Weston, and co-investigators Ben Rampton and Roxy Harris provided additional project support and input. I am also indebted to Enam Al-Wer, Werdan Kassab, Paul Kerswill, Scott Kiesling, Erez Levon, Raj Mesthrie, Jane Stuart-Smith, Christopher Tyson, and audiences at numerous seminars for comments on earlier versions of this work.

i Transcription conventions: ... = ellipsis of intervening material. $(\mathrm{xxx})=$ inaudible material. $[$ words] $=$ translated material. [IPA symbol] $=$ sound pronounced by speaker. word- = interrupted material.

ii In the older group, three individuals were not born in the UK but migrated before the age of 10 . One younger woman included is technically generation 2.5 as one parent is British Asian.

iii As self-recorders were responsible for their own recordings, the length of selfrecordings varies considerably. Rates reported for each of the four variables in 14 contexts across four speakers (a total of 56 reported rates) are based on token numbers ranging from 10-45. In a few very short recordings, low $\mathrm{N}$ values occurred (2-9 total tokens); this situation arose only for one speaker, Anwar, in the following contexts presented later in Figure 3: /1/ (maid, family, mechanic, lawyer); /o/ (mechanic, lawyer); /e/ (lawyer).

iv It is important to note that in this use of the Diversity Index, values below .5 are very unlikely because even individuals with relatively closed networks will have a minimum of two or three separate sub-groups. The Diversity Index is not equivalent to either density or multiplexity (Milroy 1987), although it relates indirectly to density.

v The detailed analysis in Sharma and Sankaran (forthcoming) shows that language transfer is a significant factor in the use of retroflexion but it is outranked by other social factors, most markedly gender. Kirkham (2011) also finds no strong bilingual transfer effect on the phonetic quality of /t/ among British Asians. 